\title{
WORKPLACE SURVEY OF COLD PROTECTIVE GLOVE AGING
}

\author{
Emilia Irzmańska*, Paulina Kropidłowska
}

Department of Personal Protective Equipment, Central Institute for Labour Protection, National Research Institute, Wierzbowa 48, Łódź 90-133, Poland, tel. +48 4264802 46, fax +48 426480222

*Corresponding author. Email: emirz@ciop.lodz.pl

\section{Abstract:}

This study presents the results of an end-of-service life survey involving workers operating in cold environments. The objective of this study was to determine whether the gloves worn in such workplaces were replaced when they exhibited clear signs of mechanical deterioration (rupture, tear, puncture, and perforation) or when they were soaked (externally) or moist (internally). The study sets out to establish whether the appearance of visible signs of damage prompted immediate glove replacement with a view to occupational safety. The calculated Cramér's $V$ values revealed weak associations between the cause of glove replacement and the frequency of glove change $(V=0.201)$ as well as the mean duration of glove use $(V=0.234)$. Furthermore, it was found that visible signs of mechanical deterioration did not prompt glove replacement. Indeed, workers continued to wear damaged or wet gloves for as many as 5 days or more.

\section{Keywords:}

Glove aging; cold work; survey; end of service life

\section{Introduction}

Hand protections against cold are utilized mainly by food industry workers during the production, storage, and distribution of foodstuffs, when it is necessary to perform tasks in facilities where cold working conditions are obligatory (e.g., cold storage areas and tunnel freezers in meat, fish, milk, cheese, ice cream, and frozen food processing plants, as well as during the sorting of frozen fruits and vegetables) [1]. Due to the adverse impact of low temperature on the human body, workers in cold climates should use appropriate protective clothing, gloves, and footwear, so that the internal body temperature would not drop below $36^{\circ} \mathrm{C}[2,3]$.

The degree of cold exposure of the hands depends on many factors, with the most important ones being source of cold (cold air, water, and solid object), temperature of the source, surface thickness and roughness, thermal conductivity of the cold object, skin moisture, blood circulation, physiology, skin condition, and temperature [4]. A particularly important factor is skin moisture, as hypothermia and frostbite affect wet skin much more readily than dry skin $\left(-5.4^{\circ} \mathrm{C}\right.$ vs. $\left.-10.9^{\circ} \mathrm{C}\right)[5]$.

Workers operating in cold environments use protective gloves characterized by high thermal insulation to prevent hand exposure to the abovementioned factors [6]. According to the requirements specified in Directive $89 / 686 /$ EEC on personal protective equipment (PPE) [7], hand protections against cold should possess thermal insulation and mechanical resistance appropriate for the foreseen conditions of use. In addition, gloves should be selected based on the type and conditions of manual tasks performed, type and duration of contact with the cold surface, and temperature range. It is also important to understand the insulation, mechanical, and hygienic properties of the materials applied in a given glove design [8].

Another domain where research is mostly needed is the study of the aging behavior of the materials used in PPE, so that the compliance to safety requirements can be ensured during the whole service life [9]. While selecting protective gloves, one should be aware of their durability or end of service life. Typically, users are not provided with such information, and gloves are replaced only following considerable wear and tear [10, 11]. Traditional protective gloves for cold working environments are made of textiles, sometimes with the addition of waterproof leather or coated materials. Materials for such gloves should be characterized by a low thermal flux penetration index in conjunction with sufficient elasticity in low temperatures to enable the performance of the requisite manual tasks [12, 13]. Temperatures below freezing point cause accelerated degradation of coated materials, which become more rigid and more prone to rupture, tear, and wrinkling $[14,15]$. In practice, this fact may lead to more rapid deterioration of the insulation properties of protective gloves. For gloves to offer an effective barrier against thermal factors, they must exhibit appropriate strength and durability and often also resistance to punctures or cuts, as any mechanical damage compromises the cold protection properties and automatically disqualifies the gloves from further use [16-18].

This study is highly relevant to the industry. One way of promoting occupational health and safety among workers in cold storage facilities is the application of suitable cold-protecting gloves. The current system of harmonized standards for testing protective gloves provides basic information about protection levels for new products and may be used for comparing them while 
selecting optimum products for a given working environment. However, the standard tests do not provide information about the estimated useful life over which gloves provide effective protection to the users. Thus, the end of service life of gloves is of crucial importance for the safety of workers. The presented results on cold-protective glove aging constitute valuable guidance helping to estimate the end of service life of gloves used in cold environments. For the workers, these findings may translate into practical information about the approximate real useful life of gloves at the workplace, which is affected by the manual tasks performed due to the mechanical aging of the gloves.

The objective of this study was to determine whether gloves worn in cold environments were replaced when they exhibited clear signs of mechanical deterioration (rupture, tear, puncture, and perforation) or when they were soaked (externally wet) or moist (internally). The study sets out to establish whether the appearance of visible signs of deterioration prompted immediate glove replacement with a view to occupational safety.

\section{Experimental}

The first stage of the study involved a workplace survey using an originally developed questionnaire to obtain information about the end of service life of protective gloves and glove material aging caused by the performance of routine tasks in cold working environments. The survey results were then analyzed statistically to determine relationships between these two factors, and in particular how the latter affects the former.

\subsection{Workplace survey}

The study involved 107 workers performing tasks in refrigerated environments in seven companies. Three companies specialized in processing meat, manual sorting of frozen products, and meat cutting and boning. Two companies dealt with manual product handling and loading. Finally, another two companies mainly offered services such as weighing intermediate products, multi-packaging, as well as product labeling. A detailed description of the companies in which the questionnaire study was conducted is given in another study by Irzmańska et al. [8].

Table 1. Participant demographics

\begin{tabular}{|c|c|c|c|}
\hline \multirow{2}{*}{ Type of work } & \multicolumn{2}{|c|}{ Gender } & \multirow{2}{*}{ Age } \\
\cline { 2 - 3 } & Male & Female & \\
\hline Production & 15 & 27 & \multirow{2}{*}{$20-55$} \\
\hline Warehousing & 39 & 6 & \\
\hline Packaging & 5 & 15 & \\
\hline
\end{tabular}

Workers were interviewed following an 8-hour shift. They told their responses to the interviewer and then filled in the form. The questionnaire used for the survey at workplaces was developed by the authors of this study and is provided in Table 2 .

\subsection{Statistical analysis}

The survey results concerning the use of protective gloves were statistically analyzed. Cramér's $V$ was calculated to determine the strength of associations between various questionnaire responses. This coefficient is based on the $c^{2}$ test of independence and measures the strength of relationships between variables, with the results expressed on nominal scales:

$$
V=\sqrt{\frac{\chi^{2}}{N \cdot \min ((w-1),(k-1))}}
$$

where, $V$ - Cramér's $V ; c^{2}-$ Chi-square value; $N$ - number of observations (here the sum of all responses); $w$ - number of response variants per one item; and $k$ - number of response variants per other item.

Cramér's $V$ assumes values between 0 and +1 . The closer it is to 1 , the stronger the association between the measured variables.

\section{Results}

\section{$\underline{3.1 \text { Workplace survey results }}$}

In terms of duration of protective glove use during the work day, the largest number of respondents (50) indicated that they wore gloves for at least 8 hours, 23 respondents wore gloves for 6-7 hours, and 15 respondents for 4-5 hours. Even fewer respondents (14) donned Gloves for 2-3 hours only, and the smallest number of respondents (10) for 1 hour or less (Figure 1).

In response to the question concerning the type of gloves used in the workplace, the largest number of respondents (34) said that they used rubber gloves; only three subjects did not use protective gloves at all. In contrast, 28 respondents circled "other," stating that they donned multiple layers of protective gloves, e.g., one or two layers of knitted gloves followed by all-rubber gloves. The reason for the common use of all-rubber gloves (a total of 73 responses) as the outer layer was that the survey was carried out in establishments processing foodstuffs. In such plants, workers are required to use rubber gloves as the outer layer to prevent biological hazards. In addition, workers also used insulated all-leather or all-leather insulated gloves (Figure 2).

In terms of frequency of removing protective gloves during a shift, the largest number of respondents (35) said that they rarely removed protective gloves, changing them only 2-5 times per shift. A slightly smaller number of respondents (32) found that they took the gloves off frequently, i.e., 6-9 times per shift. Gloves were taken off very rarely (once) and very often (10 times or more) by 12 and 15 participants, respectively. Only nine participants kept the same gloves on for the duration of the entire work shift without ever taking them off (Figure 3).

In terms of the duration of use of one pair of gloves, the highest number of respondents (65) stated that they used the same pair of gloves for 5 days or more. Fewer than one-third of the 
Table 2. Questionnaire used for the survey at workplaces

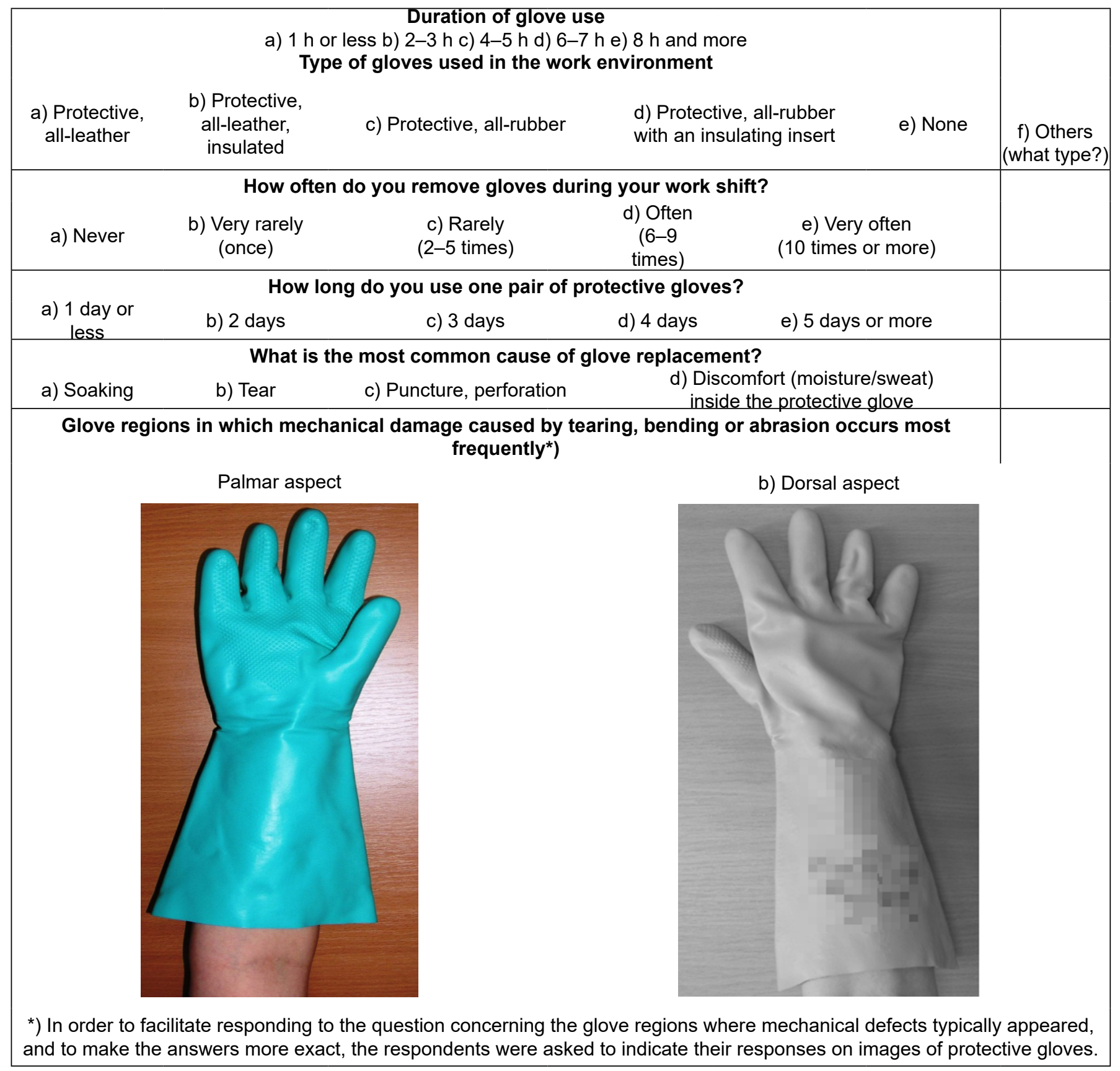

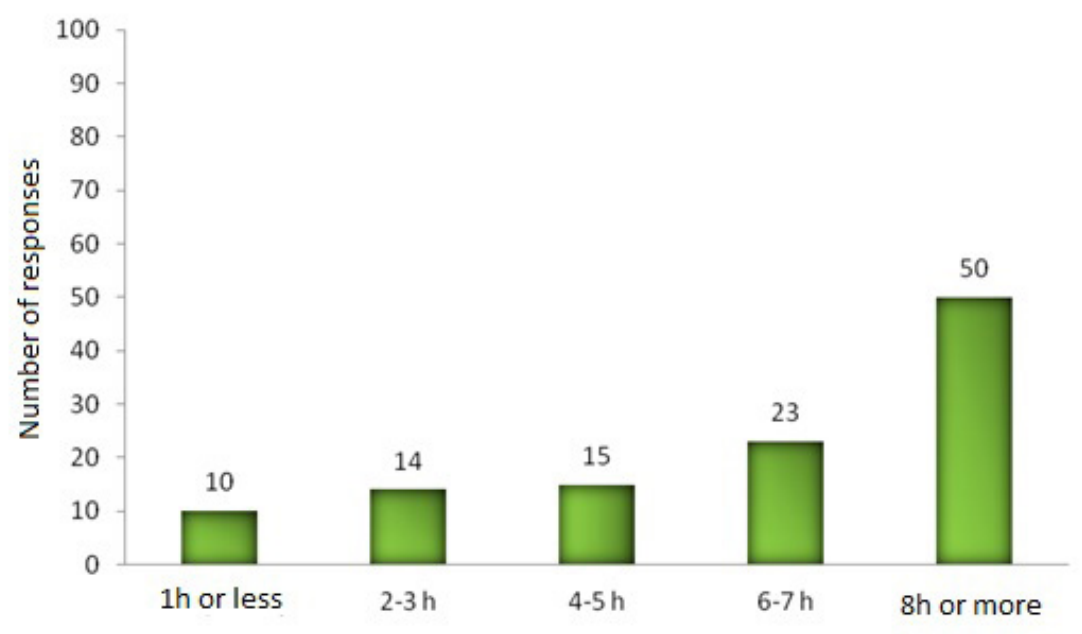

Figure 1. Duration of protective glove use by workers per shift 


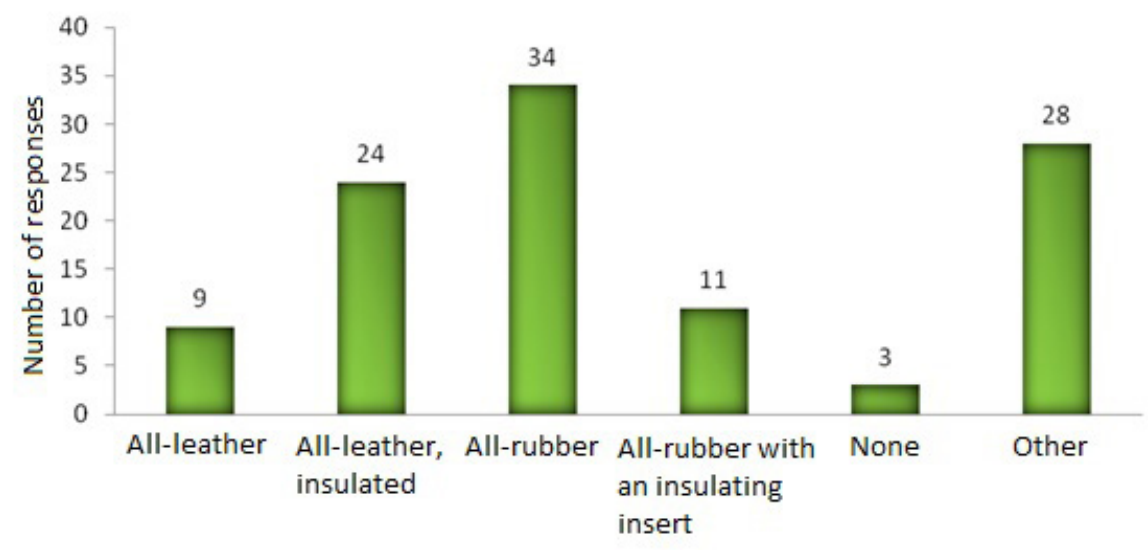

Figure 2. Types of protective gloves used by workers

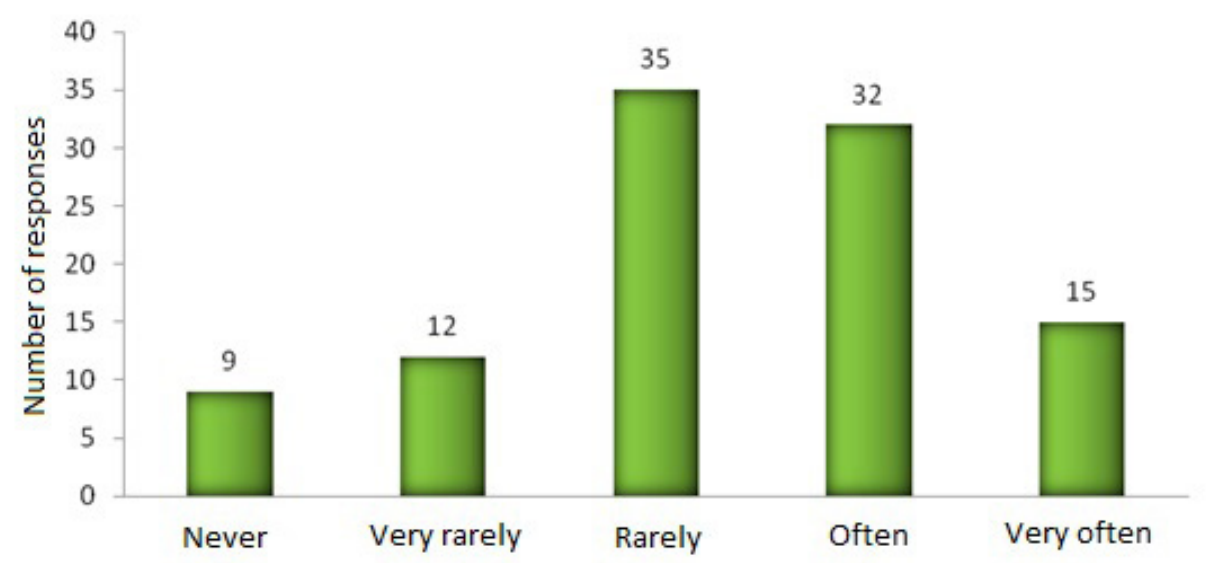

Figure 3. Frequency of removing protective gloves by workers

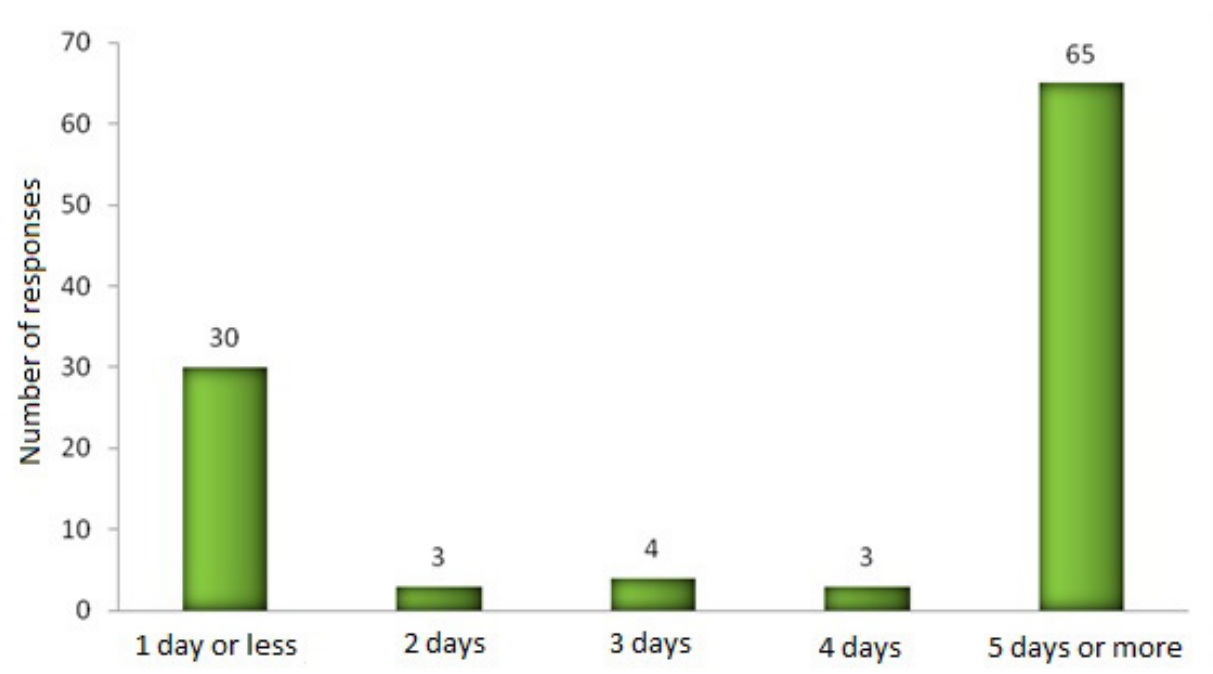

Figure 4. Duration of use of one pair of protective gloves

participants (30) wore the same pair of protective gloves for 1 day or less. The remaining respondents donned the same gloves for longer periods, three respondents for 2 days, four respondents for 3 days, and two respondents for 4 days (Figure 4 ).

In terms of the reasons for the replacement of protective gloves, the most common response among the different options provided in the questionnaire is "tear" (81 responses), followed by puncture (40), soaking (29), and discomfort (moisture/sweat) inside the protective glove (27). These results are shown in Figure 5.

In terms of glove regions most affected by mechanical damage caused by stretching, bending, or abrasion during work, the responses were distributed similarly for the palmar and dorsal aspects. The finger region followed by the metacarpus was reported to be at the highest risk of damage. Only a few respondents (12) indicated mechanical damage in 
the carpal or forearm regions. Figure 6 provides a schematic representation of the palmar and dorsal aspects of protective gloves with response frequencies marked with different colors.

\subsection{Statistical analysis of results}

Figure 7 presents the survey results that were used for calculating Cramér's $V$ to determine the strength of the association between the causes of glove replacement and the frequency of their removal. The obtained $V$ value $(V=0.201)$ indicates a weak association between the two variables.

Figure 8 shows the survey results used for calculating Cramér's $V$ to establish the strength of the association between the causes of glove replacement and the duration of glove use. The obtained $V$ value $(0.234)$ means that the two variables are weakly correlated. It was found that most workers use gloves that are quite damage resistant as the length of their use amounts to 5 days or longer. The most frequent causes of their replacement are tearing and soaking, followed by punctures/ perforations and perceived discomfort. Even if workers use prot
The summary drawn based on the statistical analysis of results is summarized in Table 3.

\section{Discussion}

Statistical analysis revealed several correlations between the variables, e.g., the duration of glove use and mechanical damage. The questionnaire made it possible to determine the duration of glove use, the types of gloves used for specific tasks, and the frequency of glove removal. The glove region at greatest risk of damage was identified.

Glove damage was established as the predominant cause of glove replacement, which means that all factors, including soaking, tear, puncture/perforation, and discomfort, affect the frequency of glove replacement (rather low). Similar conclusions were reported by Havenith et al. and Anttonen et al. [1, 15, 16].

The main causes of glove replacement were tearing or soaking of the gloves and to a lesser extent puncture/perforation or

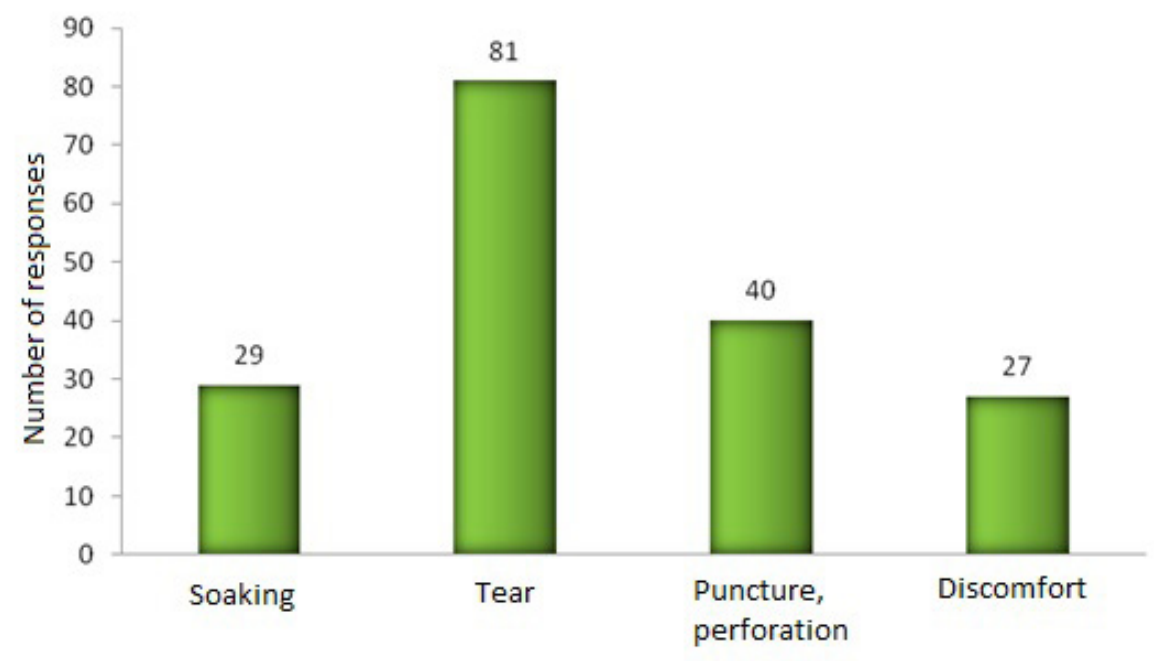

Figure 5. The most frequent causes of glove replacement by workers
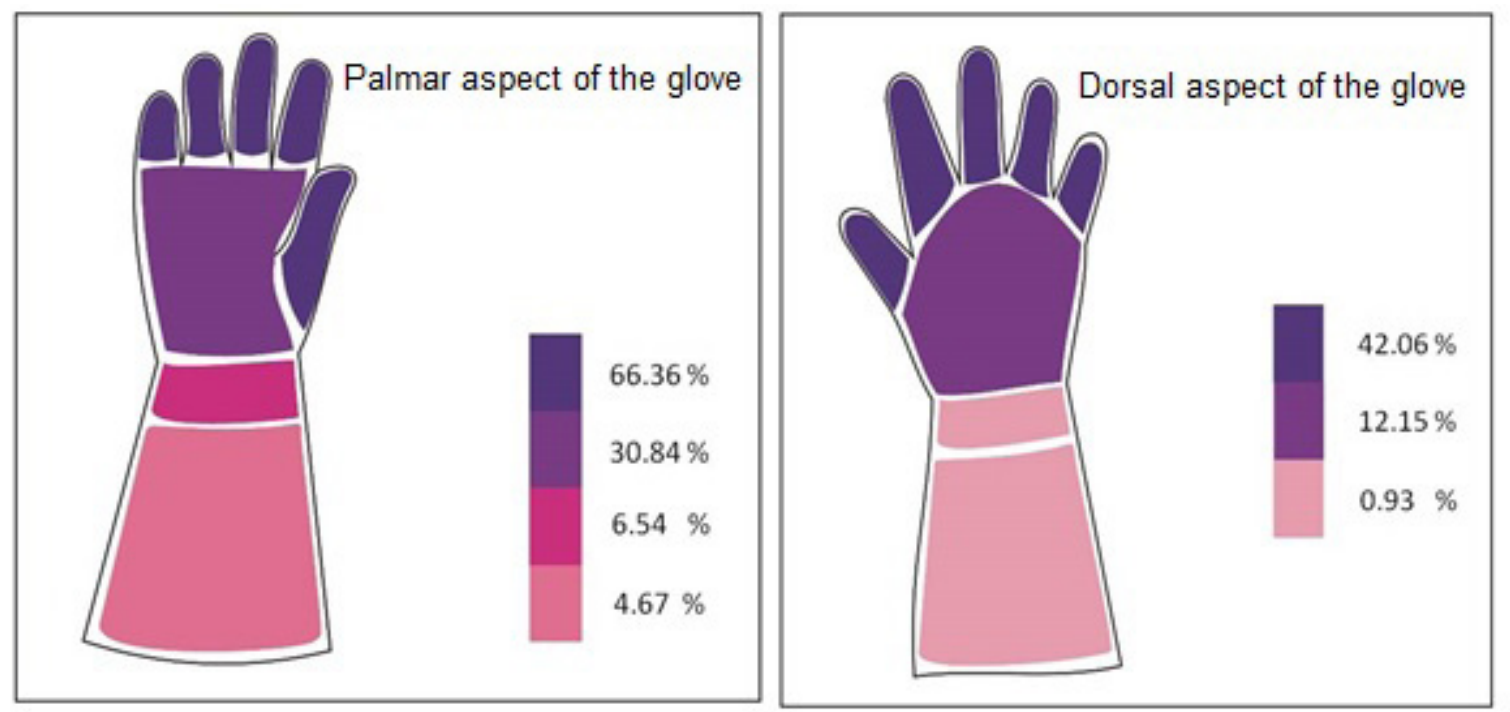

Figure 6. The regions indicated by workers as most prone to mechanical damagePercentages were calculated as the number of responses for a given option divided by the number of respondents 


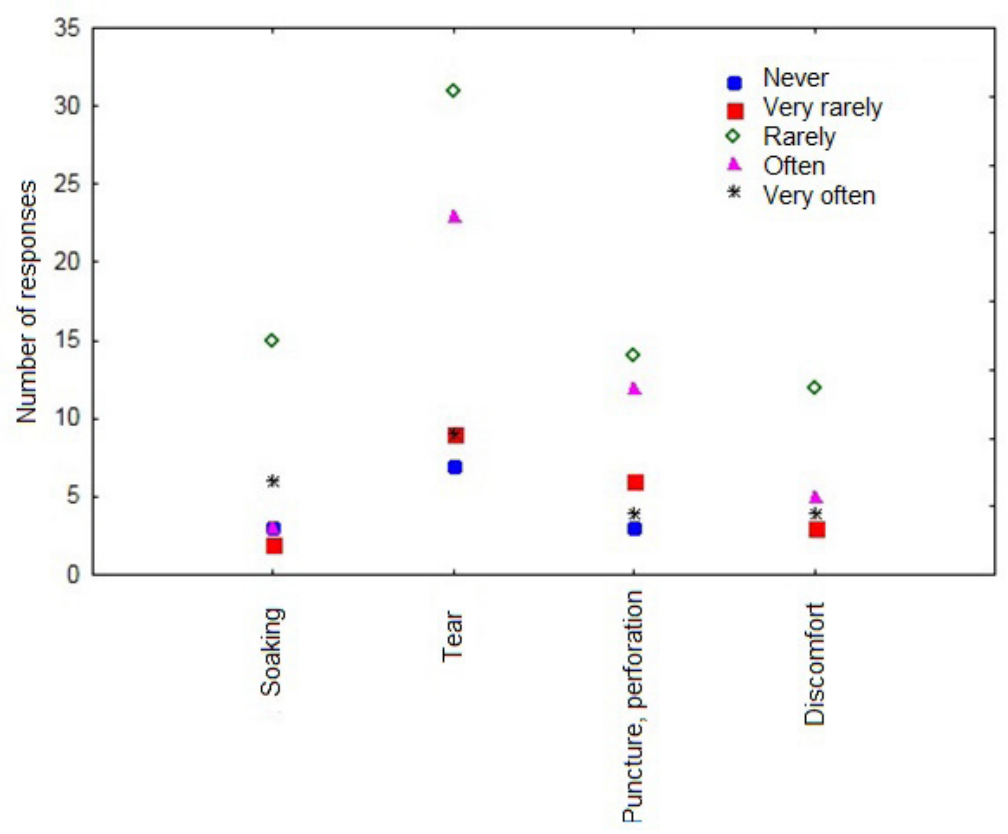

Figure 7. Association between the frequency of glove removal per 8-hour shift and the causes of glove replacement ective gloves for a day or less, the gloves are replaced most frequently due to a tear or puncture/perforation

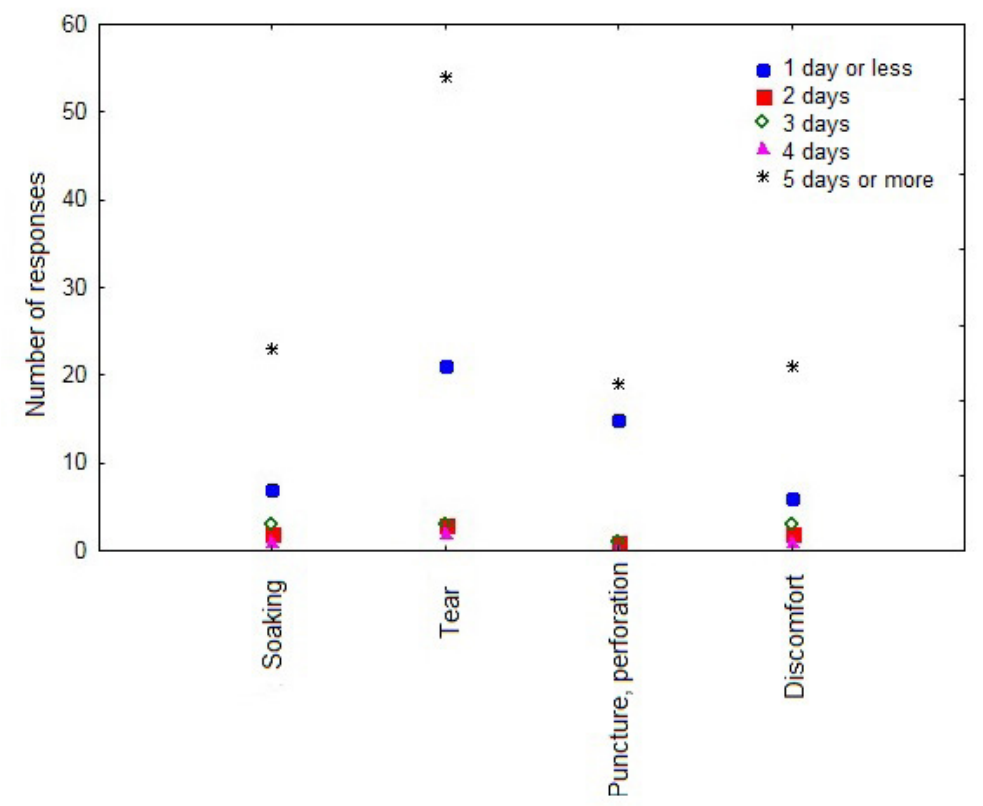

Figure 8. Relationship between the mean duration of use of protective gloves (8-hour shifts) and causes of glove replacement

discomfort. Even if workers use protective gloves for a day or less, the gloves are replaced most frequently due to a tear or puncture/perforation, which is consistent with the results of Havenith et al. $[15,16]$.

The survey has shown that the glove designs used in cold work environments do not have very good protective or functional properties. In particular, they are not very resistant to mechanical damage, especially in the finger and metacarpal regions of the palmar aspect and the finger region of the dorsal aspect. The gloves do not provide good protection from water, either on the dorsal or palmar sides. This indicates that the selected glove materials, mostly made of knitted and woven cotton coated with synthetic substances, or a combination of those materials with all-rubber gloves, fail to meet the mechanical and hygienic requirements. The tear resistance of such gloves and their cold insulation properties are rather low, and thus, they may be functionally inadequate for workplaces where workers must be protected from mechanical factors, cold, water, and moisture at the same time.

Statistical analysis has revealed that mechanical damage and discomfort arising from soaking and internal moisture rarely lead to glove replacement. Workers do not react to visible signs of glove deterioration, either, and continue to wear them (5 days or longer). This means that despite objective damage or subjective discomfort workers continue to use their gloves throughout the entire work shift ( 8 hours) or even for several 
Table 3. Conclusions from the survey on protective gloves

\begin{tabular}{|c|c|c|}
\hline Number & Conclusions & Substantiation \\
\hline 1 & $\begin{array}{c}\text { The duration of use of one pair of protective gloves is at } \\
\text { least } 8 \text { hours in a working day }\end{array}$ & Workers perform tasks in a cold working environment. \\
\hline 2 & $\begin{array}{l}\text { Insulated all-leather or all-rubber gloves are used in } \\
\text { conjunction with one or two layers of knitted gloves }\end{array}$ & $\begin{array}{c}\text { Insulated all-leather protective gloves are used for } \\
\text { tasks that do not require contact with foodstuffs. This } \\
\text { includes movement of cardboard boxes and sacks and } \\
\text { operating forklifts. } \\
\text { All-rubber gloves with one or two layers of knitted } \\
\text { gloves underneath are used for tasks, which involve } \\
\text { contact with foodstuffs, such as frozen meat, } \\
\text { vegetables, and fruits. }\end{array}$ \\
\hline 3 & $\begin{array}{l}\text { Protective gloves are removed either rarely or } \\
\text { frequently (more than } 10 \text { times per shift) }\end{array}$ & $\begin{array}{l}\text { Protective gloves are removed during breaks and in } \\
\text { cases of mechanical damage such as tear or puncture. }\end{array}$ \\
\hline 4 & $\begin{array}{l}\text { The duration of use of one pair of protective gloves is } \\
5 \text { days or longer }\end{array}$ & $\begin{array}{l}\text { Workers use protective gloves until mechanical } \\
\text { damage. }\end{array}$ \\
\hline 5 & $\begin{array}{c}\text { The most common cause of replacement of protective } \\
\text { gloves is tearing }\end{array}$ & $\begin{array}{l}\text { Gloves protecting from cold are characterized by low or } \\
\text { medium tear resistance, especially at low temperatures }\end{array}$ \\
\hline 6 & $\begin{array}{l}\text { Protective gloves are often mechanically damaged in } \\
\text { the region of fingers, both on the palmar and dorsal } \\
\text { sides }\end{array}$ & $\begin{array}{c}\text { This region of mechanical damage arises from the } \\
\text { shape of the objects handled. These objects are most } \\
\text { frequently small items with sharp edges that require } \\
\text { adequate manual dexterity. }\end{array}$ \\
\hline
\end{tabular}

days. Thus, the appearance of end-of-service-life markers seldom results in glove replacement.

Damaged gloves do not offer effective protection because mechanical damage compromises the barrier properties of the gloves and disqualifies them from further use [16, 17]. For cold protective gloves to be effective, they should preserve their thermal insulation properties and mechanical properties throughout the entire period of use [19, 20, 21]. Workers performing tasks in cold environments should be informed about the end of service life of their protective gloves and be aware of the time when it is necessary to replace them. The absence of such awareness may lead to an uncontrolled and harmful exposure to cold.

\section{Conclusions}

The abovementioned findings presented led to the following conclusions: insulated all-leather or all-rubber gloves in conjunction with one or two layers of knitted gloves are used for 5 days or longer; the most common reason for the replacement of protective gloves is tearing; protective gloves are most often mechanically damaged in the finger region both on the palmar and dorsal sides; visible signs of mechanical damage to protective gloves rarely lead to their replacement; and workers continue to use damaged and wet gloves for 5 days and more, far beyond the end of service life.

\section{ACKNOWLEDGEMENTS}

This study is based on the results of COLDPRO project: "Theuse of active ecological mineral compounds in the production of cold-protective gloves and footwear" funded in 2015-2018 by National Centre for Research and Development.

The authors thank Ms. Paulina Chęsy for her help with statistical analysis and interpretation of the results.

\section{References}

[1] Anttonen, H., Pietikäinen, P., Rintamäki, H., Rissanen, S. (2000). Cold protective gloves in meat processing industry - product development and selection ergonomics of protective clothing. In: Proceedings of NOKOBETEF 6 and 1st European Conference on Protective Clothing in Stockholm, Sweden, 212-215.

[2] Anttonen, H., Pekkarinen, A., Niskanen, J. (2009). Safety at work in cold environments and prevention of cold stress. Industrial Health, 47(3), 254-261.

[3] Holmér, I., Granberg, P., Dahlstrom, G. (2008). Cold environments and cold work. In: Stellman, J. M. (Ed.), ILO Encyclopaedia of Occupational Health and Safety, fourth ed., International Labor Organization (Geneva). Chapter 42.

[4] Chen, F., Nilsson, H., Holmer, I. (1994). Finger cooling by contact with cold aluminium surfaces: effects of pressure, mass and whole body thermal balance. European Journal of Applied Physiology, 69, 55-60.

[5] Brajkovic, D., Ducharme, M. B., Frim, J. (1998). Influence of localized auxiliary heating on hand comfort during cold exposure. Journal of Applied Physiology, 85(6), 20542065.

[6] Bellingar T. A., Slocum, A.C. (1993). Effect of protective gloves on hand movement: an exploratory study. Applied Ergonomics, 24(4), 244-250. 
[7] Council Directive 89/686/EEC of 21 December 1989 on the approximation of the laws of the Member States relating to personal protective equipment, Official Journal of the European Communities, L. 399, 30.12.1989 with later amendments; Regulation (EU) 2016/425 of the European Parliament and of the Council of 9 March 2016 on personal protective equipment and repealing Council Directive 89/686/EEC (Official Journal of the European Union L 81 of 31.3.2016).

[8] Irzmańska, E., Wójcik, P., Adamus-Włodarczyk, A. (2018). Manual work in cold environments and its impact on selection of materials for protective gloves based on workplace observations. Applied Ergonomics, 68, 186196.

[9] Dolez, P. I., Vu-Khanh, T. (2009a). Recent developments and needs in materials used for personal protective equipment and their testing. International Journal of Occupational Safety and Ergonomics, 15(4), 347-362.

[10] Irzmańska, E., Stefko, A. (2015). Simulation method for assessing the end of service life of gloves used by workers exposed to mineral oils and mechanical factors. International Journal of Industrial Ergonomics, 47, 61-71.

[11] Virgílio, A., Oliveira, M., Gaspar, A.R., André, J. S., Quintela, D. A. (2014). Subjective analysis of cold thermal environments. Applied Ergonomics, 45, 534-543.

[12] Sari, H., Gartner, M., Hoeft, A., Candas, V. (2004). Glove thermal insulation: local heat transfer measures and relevance. European Journal of Applied Physiology, 92, 702-705.

[13] Zander, J., Morrison, J. (2008). Effects of pressure, cold and gloves on hand skin temperature and manual performance of divers. European Journal of Applied Physiology, 104, 237-244.
[14] Dolez, P. I., Vu-Khanh, T. (2009b). Gloves for protection from cold weather, textiles for cold weather apparel. A volume in Woodhead Publishing Series in Textiles, 374398.

[15] Geng, Q., Chen, F., Holmer, I. (1997). The effect of protective gloves on manual dexterity in the cold environments. International Journal of Occupational Safety and Ergonomics, 3(1-2), 15-29.

[16] Havenith, G., Heus, R., Daanen, H. A. M. (1995). The hand in the cold performance and risk. Arctic Medical Research, 54(2), 37-47.

[17] Heus, R., Daanen, H. A. M., Havenith, G. (1995). Physiological criteria for functioning of hands in the cold. Applied Ergonomics, 26(1), 5-13.

[18] Holmer, I., (2005). Protection against cold, textiles in Sport. A volume in Woodhead Publishing Series in Textiles, 262286.

[19] Amir-Hashim, M. Y., Morris, M. D., O'Brien, M. G., Farid, A. S. (1997). Effect of leaching and humidity on prevulcanized natural latex films. Rubber Chemistry and Technology, 70(4), 560-571.

[20] Chen, F. (1997). Thermal responses of the hand to convective and contact cold - with and without gloves. Academic Thesis, Linkoping Universitet Tekniska Hogskolan, Arbetslivsinstitutet (Solna, Sweden).

[21] Chen, F., Holmér, I. (1997). The effect of protective gloves on manual dexterity in the cold environments. International Journal of Occupational Safety and Ergonomics, 3(1-2), 15-29. 